Journal of Intercultural Studies, 37:2, 118 - 132, (C2016 Taylor \& Francis Group

This is a post-print version (i.e. last manuscript after the peer review process) of the published article; for detailed citations please refer to the original publication, which is available at doi:

10.1080/07256868.2016.1141755.

\title{
The Art of Enduring Contradictory Goals: Challenges in the Institutional Co-construction of a 'Good Death'
}

\begin{abstract}
This paper focuses on the normative notion of 'good death', its practical relevance as a frame of reference for 'death work' procedures in institutional elder care in Switzerland and the ways in which it may be challenged within migrant 'dying trajectories'. In contemporary palliative care, the concept of 'good death' focuses on the ideal of an autonomous dying person, cared for under a specialised biomedical authority. Transferred to the nursing home context, characterised by long-term basic care for the very old under conditions of scarce resources, the notion of 'good death' is broken down into ready-to-use, pragmatic elements of daily routines. At the same time, nursing homes are increasingly confronted with socially and culturally diversified populations. Based on ethnographic findings, we give insight into current practices of institutional 'death work' and tensions arising between contradicting notions of a 'good death', by referring to decision-making, life-prolonging measures, notions on food/feeding and the administration of sedative painkillers.
\end{abstract}

\section{Keywords}

Good death; migration; death work; diversity; ageing; aged care; palliative care; Switzerland 
'Death work' is part of daily business in nursing homes, and nursing home staff establish routines of professional care for the dying elderly. From an institutional perspective, these routines of 'doing death' must comply with organisational constraints and at the same time allow for a dignified individual death. Focusing on institutional elder care, this paper explores the dimensions of 'doing death' when the elderly involved are of migrant background. It is argued that the way institutions 'do death' is tailored to a specific conception of a 'good death', which may be challenged by migrant dying. Drawing on classical social interactionist studies on dying (Sudnow 1967, Glaser and Strauss 1968), we will focus on the coconstruction of 'good death' in interactions between residents of migrant background and professional care workers (often of migrant background themselves), and on processes of 'doing diversity' while 'doing death'. The paper is based on the research project 'Doing Death and Doing Diversity in Swiss Nursing Homes' funded by the Swiss National Science Foundation as part of a broad National Research Programme on 'End-of-Life' (NRP67, grant number 406740_139365/1). The data presented show that contemporary 'death work' in Swiss nursing homes is constituted by implicit notions of 'good death', which may collide in concrete interactions around migrant 'dying trajectories', the latter being understood in this paper as a broad and open focus on processes of dying, not in the sense of a tool to predict death and to guide professional practice (Glaser and Strauss 1968).

\section{Notions of 'good death'}

The concept of 'good death' builds on a well-documented tradition of sociological, anthropological and historical analyses of dying in modern societies (see, for example, Ariès 1981, Hart, Sainsbury and Short 1998, Kellehear 2007, Green 2008, Hahn and Hoffmann 2009). What a distinctive society regards as a 'good death' is in this strand of literature generally linked to societal modernisation and individualisation processes. While the way societies dealt with dying in classic modernity was characterised by a discourse of denial and displacement (Ariès 1981; for a critical overview, see Hahn and Hoffmann 2009, p. 128ff), societies in conditions of 'reflexive modernity' are confronted with a new visibility of death and the philosophical reflections that accompany it (Bonss and Lau 2011). Dying is increasingly individualised (McNamara 2004, Seale and van der Geest 2004) and the ideal of 'good death' is increasingly subject to public debate (Green 2008). What is at stake nowadays, especially in contexts of old-age dying and dying of degenerative diseases, is the question of keeping control by shaping and 'timing' death (Kellehear 2007), for instance by suicide or euthanasia (Kruse 2007, p. 166ff).

A characteristic feature of dying in contemporary Western societies is its delegation from the home/the family/the community to professional institutions: dying and death are 'outsourced' to hospitals, hospices and nursing homes (Hahn and Hoffmann 2009). While death in nursing homes has always been a part of daily routine which is rarely reflected upon, hospitals became highly specialised, almost omnipotent institutions of restoring and prolonging life, in which death is connoted with institutional failure (Sudnow 1967, Glaser and Strauss 1968). Consequently, the hospice movement emerged as an initiative to reclaim some space for dying and grieving. Hospice discourse has taken over the analytical concept of 'good death' and has transformed it into a normative concept, which is currently entering 
policies and public discourse. There is increasing awareness also within mainstream healthcare services that health care is not only curative (i.e. healing) but in many cases also palliative (i.e. soothing). In consequence, the concept of palliative care (in contrast to curative care) is currently emerging in the Swiss health-care system, not least within biomedical discipline, and services specialising in palliative care are developing both within and parallel to hospitals.

The hospice movement and its reception within mainstream medicine have brought about a rather distinctive normative notion of what a 'good death' is: namely, an individualized and self-determined dying in dignity, peacefulness, preparedness, awareness, adjustment and acceptance (Hart et al. 1998). The biomedical prolongation of life at all costs is giving way to the ideal of stopping life-supporting treatments at the end-of-life and instead focusing on pain relief and quality of life. Referring to the Swiss National Strategy on Palliative Care (FOPH and $\mathrm{CMH}$ 2012) as an example, palliative care is characterized by an orientation towards the values of self-determination, dignity as well as acceptance of illness and dying. In accordance with the World Health Organisation's definition of palliative care, the Swiss strategy also highlights that caring for the dying should not only soothe physical pain, but also address psychosocial and spiritual needs. Furthermore, palliative care is inspired by the idea that all members of society should have equal access to it.

This conception of dying a 'good death' is, however, tailored to autonomous patients suffering from malignant diseases such as cancer, where a death prognosis is relatively clear and a certain time of preparation for death may be expected (see Kellehear 2007). The capacity to be aware and self-determined furthermore needs a considerable amount of resources, mainly knowledge and communication skills (Schneider and Stadelbacher 2012) but also economic and social resources. The above-described contemporary notion of a 'good death' is an ideal shared in particular (secular, individualistic, Anglo-Saxon) societies (Walter 2012) and mainly compatible with well-educated, middle-class, middleaged individuals. As will be shown below, this implicit frame of reference is not necessarily shared by all the actors involved in 'dying trajectories', especially - however not only - when migrants are involved.

\section{Negotiations of diversity and migration}

As a recent literature review of migration and palliative care (Soom Ammann and Salis Gross 2014) has shown, there is a considerable body of academic writing about palliative caregiving when faced with dying patients of migrant background and their relatives. The literature clearly shows that needs, expectations and specific understandings of central concepts may collide at the end-of-life (see Spruyt 1999, de Graaff et al. 2010). What is a 'good death' for the Western biomedical professional may therefore be different from what the patient, their relatives or their community regard as being a 'good death'. Conflicts arise in the absence of an adequate negotiation of differing needs and expectations between all the actors involved in a 'dying trajectory'. Moreover, tensions may also arise due to unsuccessful negotiation processes. Professionals may for example be irritated by relatives' refusal to allow medical staff to communicate openly with the patient (for example, 
concerning a bad diagnosis or prognosis). Equally difficult from a professional's viewpoint is the refusal to engage in active decision-making (for example, on whether or not to stop treatment) and the insistence on life-prolonging measures or decisions perceived as not compatible with professional ethics (Soom Ammann and Salis Gross 2014).

Underlying these conflicts are diverse cultural, religious or ideological reference systems of what a 'good death' should be like, as the literature suggests and as we will show in detail in this paper. Such frames of reference shape interactions on an implicit level (see 'implicit knowledge' in Giddens 1984). Transforming them into explicit knowledge as a basis for mutual negotiation and consensual decision-making is in practice a very demanding task involving the risk of threatening 'ontological security' (Giddens 1991, Gunaratnam 2008). Specifically, although migrant dying may show very obviously how divergent notions of 'good death' can collide, these conflicts do not only occur when migrant dying is at stake, and they do not only occur between 'death workers' and relatives, but also among relatives and/or among 'death workers'.

\section{'Good death' in institutional aged care}

Dying in contemporary modern societies is characterised by longevity: 'natural deaths' at very old age (in opposition to infectious, accidental or violent deaths) are increasingly common. But instead of being the idealised (for instance, controllable and arranged) 'good death', in practice it is often a slow and socially isolated dying process in institutional settings of specialised organisations (Hoffmann 2011), characterised by 'shameful' loss of autonomy and dignity (Kellehear 2007). Therefore, end-of-life in very old age is on the one hand becoming common, but on the other hand, often does not fulfil the ideals of individualised, self-defined and self-controlled dying.

In late-modern societies, caring for elderly in nursing homes is a well-established longterm care option (on Switzerland, see Hoepflinger et al. 2011). Due to the general trend in elder care to maintain individual autonomy as long as possible and to transfer persons to institutional care as a last option, nursing homes are increasingly becoming institutions of dying, comprised of residents at very old ages, with advanced multi-morbidity and short duration of stays. In Switzerland, institutions for long-term care are now the most common place of death for the population aged 80 and more (Hoepflinger et al. 2011, p. 100). Yet, both research and organisational initiatives still tend to focus on the hospital and specialised palliative care services (see for example, Pleschberger 2007). Furthermore, while in the context of public debates on 'dying well' there are increasing expectations on nursing homes to provide individualised high-quality care, the old-age long-term care sector is under pressure to save costs and is highly affected by shortages of qualified staff. Long-term care institutions are therefore challenged by efficiently providing 'good deaths' to an increasingly pluralised population of elders with a highly diversified staff regarding qualifications, professional careers and national origins.

Issues of 'doing death' while at the same time 'doing diversity' (on the concept of 'doing', see West and Zimmerman 1987) are therefore expected to be at stake in nursing homes, but 
resources to practice 'good deaths' in this context are limited. The research project from which our data are drawn explored the current practices of dealing with dying and diversity in two Swiss nursing homes that offer standard services for elderly residents in need of care. Both nursing homes are situated in an urban environment within neighbourhoods characterised by heterogeneous populations, including migrants. The two homes care for approximately 120-130 residents each. Nursing home A provides single rooms and is organised in households, one of them offering migrant specific services to 'Mediterranean' residents. These residents mostly migrated as 'guest-workers' from Italy several decades ago. Nursing home B provides mainly double rooms and is organised in wards without specific specialisations in care. In both organisations, the first and second authors conducted extensive ethnographic fieldwork (nine months of participant observation and interviewing) to understand how end-of-life in nursing homes is constituted, how dying and death are 'done' through daily interactions and how diversity issues are at stake in this 'doing death'. Our research methodology followed the principles of Grounded Theory: we entered the research field with a very open research question, data were collected through observation and informal talks with carers, residents, relatives and other actors present in the field, and recorded in extensive field notes. Interviews were selectively audio-recorded (if circumstances allowed for it) and transcribed. The material was edited and analysed in German; for the purpose of this article, selected data were translated into English by the authors. Data analysis followed the classic, theory-generating principles of Grounded Theory assisted by ATLAS TI software. Following the ethical standards formulated by the Swiss Ethnological Society, approval was granted by the management of the two nursing homes. Research participants were initially informed orally on the aim of the research project, and their willingness to participate was constantly re-evaluated by the researchers in concrete interactions.

For the purpose of this article, our selection of data and analytical focus centres on residents with migrant background. While in other papers we elaborate migrant and ethnic diversities in more detail and not only among residents but also with respect to staff and field researchers (see van Holten and Soom Ammann 2016), in this paper we focus on the staff's role as professional carers in dying trajectories, meaning, their 'death work'. This is also in line with our observations in the field that carers tended to strongly focus on their professional roles in their 'death work', and that they treated the two field researchers (first and second authors, both native Swiss) primarily as staff members, despite the authors' repeated and at times also rather explicit enactment of their researcher roles during participant observation in the field.

\section{'Death work'}

In approaching 'death work' and its professional procedures of everyday 'doing death' in the nursing home, we refer to the classic study of hospital 'death work' by Sudnow (1967). In this context, 'death work' refers to professionalised routines of those who are occupationally involved in 'doing death'. In the nursing home context, this is mainly referring to care workers of a variety of qualifications (nurses and nursing aides), but also to other occupational actors such as doctors, specialised nurses, social workers, spiritual specialists, cleaning and housekeeping personnel. The main duty of 'death work' involved in Swiss 
nursing home 'dying trajectories', however, remains with the nurses and nursing aides working on regular day or night shifts. In focusing on 'death work' in this paper, we emphasise 'doing death' from an organisational perspective of professional practice, within an institution defining more or less strict social rules to guarantee its functioning and the fulfilment of its tasks (see for example, the 'total institution', Goffman 1961). From this perspective, the everyday 'death work' of the institution's professional care workers is to be understood as a form of agency with considerable scope for flexibility, but nevertheless obliged to fulfil the requirements of the institution. Therefore, 'death work' tends to focus on routine procedures and avoidance of disruptions to routine (Sudnow 1967, p. 169).

Our analysis has shown that the normative notion of 'good death', inspired by hospice ideology (Hart et al. 1998) and in practice adapted to a 'good enough death' within the institutional logics of professional palliative care (McNamara 2004), has also diffused into the nursing home, but in a very practical and intuitive manner. While nursing homes for several decades were oriented towards curative medical practice, they are now starting to shift their orientations towards ideals of palliative care (Kostrzewa and Gerhard 2010). Both orientations are present in everyday practice and shape negotiations about concrete care actions among staff and between staff and relatives, especially in the last days and weeks of life. Residents of nursing homes, however, are often not explicitly involved in decisionmaking and in negotiating care. On the one hand, this is due to the fact that residents increasingly enter the nursing home with severe cognitive restrictions (such as dementia). On the other hand, speaking openly about death and dying remains a taboo for this generation, especially in the vulnerable moment of having to enter a nursing home (Salis Gross 2001). It is furthermore still very uncommon that residents have drafted 'living wills' to state their wishes for end-of-life care, even though promoting such advance directives is presently one of the main instruments of policymakers to publicly enhance selfdetermination in dying. Compared to other dying institutions, the nursing home is thus confronted with a rather specific form of dying:

In most cases you can accept death. It is normal, part of daily life in the nursing home. The residents have had their lives and it is natural that it comes to an end. (Nurse, Daria, Organisation B)

In this sense, dying at a very old age in a nursing home may be seen as a 'good death' since it is at the right time, after having lived a long life. 'To be able to go' or 'to let go' are standard expressions in the nursing home to talk about dying, without having to be too explicit about it. These two notions furthermore point to the dominant conception of dying understood as an individual, self-determined action. What Daria describes above is the ideal of a 'natural' death where the resident decides when it is time to die and the carer only has to make sure that nothing is hindering the passage. 'To allow it' or 'to let it happen' are common terms to talk about the role of the carers. In practice, this is most often interpreted as making sure that the resident is not disturbed unnecessarily, that he/she is lying comfortably and does not feel dehydrated. To ease physical suffering and anxieties, morphine is widely used by the 'death workers'. 
There are, however, also 'bad' or even 'terrible dying trajectories' that arise unexpectedly, are not controllable or seem to be unclear, necessitating decisions to be taken. Such decisions lie heavily on the shoulders of the care staff and always contain the risk of taking the wrong decision, as nurse Marina describes when talking about the sudden, indistinct deterioration of a resident:

I was alone that day, had to bear the whole responsibility. I called her daughter, and she said: Well, what do you think, is it really an emergency? She did not want to decide. [...] Then I called the doctor, told him how it was, and he said: 'Well, if she stays with us in this condition, she's going to die. What do you think should be done?' [...] I told him loud and clear that I am not in a position to decide about life and death! This is something the relatives have to decide, maybe together with the doctor, but not me! (Nurse, Marina, Organisation A)

Marina was in this case in an extraordinary situation, but what she articulates here is something constantly present in the caring work of the nursing home, making it implicitly also a constant 'death work' potentially loaded with guilt (Salis Gross 2001). Our data show that the threat of taking wrong decisions and the implicit possibility of being guilty, which is involved in 'bad' or 'terrible deaths', may lead the professional carers to strive for reconstructions of 'good deaths' (see also Simpson 2001) by investing in 'death work' practices regarded as elements of 'good deaths'. Such strategies include paying more attention to residents perceived as 'difficult' or 'suffering' in terminal phases by spending more time in their rooms, holding their hands or taking over an advocacy role for them. Another strategy to transform 'bad deaths' into 'good deaths' is telling stories about the resident stressing positive aspects of their everyday lives in the nursing home. Furthermore, the preparation of dead bodies seems to be an important occasion to recast 'bad' or 'terrible deaths' as 'good deaths' by investing in preparing deceased residents in an especially 'beautiful' way, trying to give them a bodily expression of peace and dignity, decorating the deathbed with flowers, etc.

To me it is very important that a dead person looks peaceful, calm, relaxed. We give our best to make the person look nice. It is like a last favour, to make her or him look the way they looked before the suffering started. It is not only for us but also for the relatives. This last picture must be peaceful. It helps a lot to let go. (Nurse, Katha, Organisation B)

Thus, the 'death work' of professional care workers in nursing homes is a constant process of 'doing death' on behalf of the residents. The aim of 'doing' such deaths as 'well' as possible is a shared professional norm for all care workers, but the ideals of palliative care underlying it (as described above) are not known in detail to all of them. Balancing the everyday need to take decisions on behalf of dying residents by interpreting what is to be done to make their individual dying a 'good death' is therefore a demanding task for carers working in nursing homes: 
It's a very complex thing to take decisions in such situations, and it is mostly about insecurities. One feels the need to do something, instead of reflecting on the situation and on the possibilities one has, and here many of us are - yes, they are somehow incapable. It is a demanding task. You need to be able to think in complex terms, to step back, to discuss, to find consensus. Yes! And you certainly are quicker giving an antibiotic or calling an ambulance. (Team leader, Charlotte, Organisation A)

In consequence of the fact that residents often do not or cannot explicitly say how they intend to die before they become terminally ill, decisions about their care in the last weeks and days have to be taken over either by the staff or by the relatives. Although Swiss law gives clear priority to relatives to decide about medical issues, the carers sometimes feel that they are in a better position to decide for the residents since they are the ones sharing everyday life with them, not the relatives. If relatives delegate decisions to the staff or if there are no relatives, the staff members make decisions by reference to their care directives and their personal relationships with a resident (if they for example keep the door open or closed, put the light down, inform other residents, and so on). And, most importantly, they rely heavily on interpreting minimal bodily signs according to their experiences with this resident, to interpret for example if they want to eat or drink, are at ease or in pain. The considerable diversity among staff in terms of their professional training and biographical experiences serves as a frame of reference for individual carers to interpret what is appropriate, as the following case studies will show.

\section{The challenge of 'doing a good death': case studies}

To illustrate the points of tensions in providing for a 'good death', four case studies will now be discussed. They focus on practices of adjusting professional 'death work' procedures in order to deal with diversity.

\section{The 'uneased dying trajectory'}

Mr S., a German migrant who had lived in Switzerland for 20 years, was a member of a Protestant Free Church. He entered nursing home B at the age of 80 . The staff described him as a polite man who led a secluded life (as far as this is possible in a nursing home). He died two years later of lung cancer. In his last days and hours of life he suffered from severe chest pain and had difficulty breathing. Nevertheless, Mr S. continued to verbally reaffirm his will not to receive sedative pain therapy. He wanted to die and 'face God' with a clear mind, as he repeatedly stated. Samantha, the nurse in charge of the nightshift during the very last phase of his life, was extremely challenged by the resident's will. For her, a professional 'death worker' with years of experience in a hospital palliative care unit, standing at the bedside of Mr S. who was agitated, short of breath and 'moaning from pain' proved to be hard to bear. Having the morphine 'always in the pocket' ready to be administered, but explicitly not having the resident's permission to use it, literally rendered her powerless, as she stated. Nevertheless, complying with the legal directive that respect for the individual's 
will takes precedence, she did not administer any strong analgesia, and the resident died in the early morning hours.

In contrast to most 'dying trajectories' we observed in the nursing homes, $\mathrm{Mr} \mathrm{S}$. acted as an autonomous, self-determined individual who clearly expressed his will until the very end of his life. His understanding of a 'good death' led to a 'dying trajectory' that was difficult to accept for the professional 'death worker', whose procedures for 'doing death' focus on easing the resident's pain and thereby making dying 'bearable' for the resident, but also for all the other actors involved. It may be argued that a resident who substantially and consciously shapes his dying himself is to be considered as the ideal patient in palliative care. However, the way Mr S. wished to 'do' his death collided with the nurse's notion of 'good death'. Referring to her own reference system as a professional 'death worker', she felt under pressure to produce a 'good death' in the sense of reducing suffering. She would clearly have preferred to control the situation by alleviating pain instead of accepting the resident's deliberate choice to suffer. Surrendering to his will therefore implied a severe disturbance of her routine as an institutional 'death worker' who is not only taken to her limits by tolerating an opposite view of 'good death', but who at the same time had an obligation to be concerned about collective well-being on the ward. A resident who is moaning from pain during the night also disturbs the other residents, most notably the roommate. This will not only prevent them from sleeping, but also confronts them with their own vulnerable situation. The carer may feel exposed to questions regarding her professional capacity (was not there anything you could do for him?) and guilt (why did not you help him?). Additionally, caring for a dying resident during nightshift, where one nurse is responsible for thirty residents, is already more difficult to organize than during dayshift when more staff are available. In case of a sudden deterioration (such as threat of suffocation), the situation might demand her full attention at a time when other residents should be repositioned, helped to go to the toilet and so on. Residents under sedative and analgesic medication are in this sense easier to control and cause less disruption to the carers' work duties and to the well-being of the other residents. Surrendering to Mr S.'s will, therefore, also meant giving up control over this 'uneased dying trajectory'.

\section{The 'guilt-ridden dying trajectory'}

Mrs A., having migrated from Sri Lanka in the 1980s, came to nursing home B after a cancer incident at age 71 , being unable to control her legs. She was appreciated as a lovely person by staff and fellow residents, integrating well into the ward, not posing any challenges, and being frequently visited by her husband and son. Her terminal phase began rather unexpectedly a few months after her entry to the nursing home with sudden and severe pain. The nursing staff did not immediately succeed in their attempts to control this heightened pain with adequate morphine doses. At the same time, according to the standard procedure of the nursing home, her relatives were regularly informed about the deterioration of her condition. On the day of her death, husband and son were asked early in the morning to come by. Katharina, the nurse in charge, wanted to tell $\mathrm{Mr} \mathrm{A}$. that she thought Mrs A. was actually dying now. Although the son translated this to his father, the nurse was not sure if the latter understood the information she wanted to pass on. In the next hours, the husband stayed with his wife, more and more puzzled that he could no 
longer talk to her as she was now unconscious. Feeling that she had to justify her procedure, the nurse explained that Mrs A. was feeling 'very sleepy' since she had received morphine and other strong opiates and that she, the nurse, was grateful to see that Mrs A.'s suffering seemed to be eased now. However, Mr A. demanded that the morphine be reduced in order to be able to talk to his wife. Later, he demanded the intervention of a heart-lung machine to keep his wife alive. He mentioned that Mrs A.'s mother had to come and see her daughter, but that she would need another day to travel to Switzerland. The professional 'death worker', considerably irritated by this request, was not willing to acquiesce since she regarded it as an unnecessary prolongation of Mrs A.'s obvious suffering in order to comply with someone else's needs. In accordance with the nursing home doctor's advice and the patient's earlier statement that she did not want any life-prolonging measures, the nurse continued to give high morphine doses. Shortly afterwards Mrs A. died without regaining consciousness. Standing beside the deathbed at that moment, the husband expressed his suspicion that 'they made her go' by giving morphine. Katharina, taking Mr A.'s hand and looking straight into his eyes, replied that it was the cancer that had killed his wife, not the medication. Minutes later, the husband expressed the wish that his wife be dressed in her wedding sari. Katharina, now that the hectic rush of the 'dying trajectory' was over, encouraged him to retrieve the sari while the dead body was washed and prepared for the dress.

Mrs A.'s 'dying trajectory' came on unexpectedly and progressed rapidly, causing visible suffering and thereby putting the professional 'death worker' under heavy pressure to react. Nevertheless, from the perspective of the staff, their procedures of care for the dying resident may be seen as successful and executed according to the nursing home's routine: referring to the palliative care standards, the resident's relief from acute pain and respect for her stated wish not to receive life-prolonging measures constitutes the appropriate frame of reference for professional 'death work'. It therefore could be argued that from the point of view of the professionals and the resident a 'good death' was (at least partly) produced. The collision in this case arises between professionals and relatives. On the one hand, there is not enough time and attentiveness from the professional's side to also consider the husband's conflicting needs. Not only does he express his needs late in the 'dying trajectory', but also rather unexpectedly, thereby upsetting the 'death workers" characterisation of him as a compliant person who is grateful for every help his wife receives. On the other hand, there is not enough power on the husband's side to insist on his view of a 'good death', namely to be able to say goodbye to those who are important (but who may not be nearby when migration is involved), and to do everything possible not to 'make somebody go'. After the death of Mrs A. and the husband's sudden accusation, Katharina shows considerable tolerance in allowing the husband enough time to retrieve his wife's wedding sari and in organising 'cultural experts', namely staff members of Indian migrant background who, as Katharina supposes, should also know how to wrap a body in a sari. By doing so, the nurse accepts that the professional routine of preparing a dead body quickly and with clothes available nearby is disturbed. It might be argued that she thereby tries to convert a 'guilt-ridden dying' into an experience which also includes elements of a 'good death' from the perspective of the husband.

\section{The 'unprotected dying trajectory'}


Mr R., suffering from advanced dementia, was a resident for almost a decade in nursing home B. When ward leader Beata talks about his terminal phase and death, she mainly talks about the relatives. From the beginning, she says, Mr R.'s children were always very emotional about their father, and she experienced them as rather domineering towards the staff. She says that they explicitly questioned on repeated occasions if Mr R. was being adequately cared for since the staff were not in a position to understand his 'Italianness', as they put it. As a manifestation of this point, the relatives used to come by every evening and bring home-made food, which they fed to him. When Mr R.'s condition deteriorated towards the end of his life, he did not talk any more, he was not able to get up, and he stopped eating autonomously. At this point, the relatives increased their presence in the nursing home and, even though Mr. R. did not swallow anymore, they continued trying to feed him with their own food. In Beata's words, they 'prodded him, opened his eyes, stuffed him', they literally 'forced' him to eat, and they told the staff that 'food would keep their papà alive'.

It was, as Beata says, very difficult for the relatives to understand why the staff did not feed their father anymore in the morning and at lunchtime; they thought that the staff were going to let him starve. Opposed to this, Beata would have preferred to stick to the usual procedure of professional 'death work' in the nursing home, whereby not swallowing food autonomously is interpreted as a 'refusal', i.e. an expression of the resident's will that has to be respected by professional 'death workers'. Therefore, the relatives' insistence on eating not only collided with the usual procedures of the nursing home carers, but their 'prodding' and 'stuffing' was experienced by the staff as a veritable assault on Mr R., which would necessitate protection by the professional 'death workers' responsible for his well-being. On the other hand, close relatives are by law the first proxies for patients, and therefore Beata's professional understanding of 'doing good death' also demanded compliance towards relatives' wishes. She therefore tried to balance her advocacy for the resident with the wishes of the relatives to 'keep their papà alive'. However, the relatives' conflicting views of how to properly care for their father, together with their domineering behavior towards the staff and questioning of their professionalism, were a key structuring element of the relationship between carers and relatives which Beata did not succeed in resolving. Even after Mr R.'s death, the relatives continued to make claims on the staff and expressed 'strange' wishes: they wanted their father to be dressed in a black suit, including shoes and hat, something that bewildered Beata.

Beata's narration of Mr R.'s death is an example of a 'dying trajectory' in which the patient's agency was absent. As is stipulated by law, his children took over as his proxies. What was challenging for the professional 'death worker', however, was that the relatives referred to a vision of 'good death' conflicting with her view. The relatives clearly insisted on doing everything possible to prevent death. Furthermore, they were very active in doing what, as they thought, was within their power to provide for a 'good death': making sure he ate what they cooked for him. Beata clearly disapproved with this interpretation of a 'good death'. She would have stuck to what palliative care standards suggest, namely accepting that the patient was signalling his wish to die and therefore allowing him 'to go'. Beata tried to be tolerant but succeeded neither in convincing the relatives of the usual procedures of 'death work', nor in preventing them from enacting their roles as 'caring relatives' in the nursing 
home. While she was not able to accept their behaviour in the terminal phase, she did, however, partly surrender to the conflicting expectations of the relatives after death by dressing $\mathrm{Mr} \mathrm{R}$. in a hat and shoes, clothing that did not comply with the standard procedures for preparing a corpse in this nursing home. While it might be interpreted that by doing so she was (partly) successful in enabling the relatives to 'do' their father's death as they felt was appropriate, she was obviously left with a bad feeling, leading her to generalise from this experience that Italians as an ethnic group are difficult nursing home customers. This may be interpreted as a strategy to deal with the potential guilt of having failed in protecting the resident from assaults on his right to die in peace by locating the explanation outside of her scope of agency, namely in the supposedly ethnic nature of the relatives' behaviour.

\section{The 'indecisive dying trajectory'}

Mrs I. was a severely demented Italian migrant living in the 'Mediterranean' ward of nursing home A for several years. She was rather mobile, but had retreated to only speaking a local dialect nobody else in the ward was able to understand, and she had been eating and drinking badly ever since she entered the nursing home. During a heatwave period in summer, she developed a fever and diarrhoea, and she no longer got up or even reacted to the carers' presence any more. After some discussions between the doctor, the nurse in charge (Marina) and the daughter, it was decided to send Mrs I. to hospital, where dehydration was diagnosed. After a few days, Mrs I. was returned to the nursing home and seemed to have recovered somewhat. Nurse Marina admonished the staff that dehydration in Mrs I.'s case was a failure to have cared properly for her, since she always had to be encouraged to drink. Feeling guilty about Mrs I.'s condition for not having paid enough attention to her drinking, Marina was in a state of increased attentiveness.

Mrs I. then seemed to have more difficulties in swallowing liquids than she had before. The doctor called the daughter to discuss what was to be done. He suggested the option of prescribing a hydrating infusion to give Mrs I. a chance to further recover, but he could not tell if she would. He wanted the daughter to decide, but she refused and instead called for her brother, who was living in Italy. He travelled to the nursing home, but could not decide either. Marina and the doctor saw that he was crying and therefore decided to give Mrs I. an infusion: this also gave her son some time to accept that his mother might be about to die. Mrs I. got the infusion, and nurse Marina eagerly observed her condition during the following days. However, Mrs I. did not show any clear signs if she was recovering or 'only kept alive by the hydrating infusion'. Marina felt that it was necessary to take a decision, but perceived this as 'a decision over life or death', which she was not willing to take since for her there were no unambiguous signs. Referring to the palliative care ideal of respecting the patient's will, she said that she was not able to come to a clear conclusion on Mrs I.'s wish to live or die. Was Mrs I. at all in a position to express her own will due to her advanced dementia? Did she still have quality of life? Was she suffering, or was she at ease? Due to the absence of distinct physical signs, Marina insisted that the relatives decide, or at least clearly express that they would accept it if the staff decided to remove the infusion. It took several conversations with the daughter, the son, the doctor, a nurse colleague and the team leader to come to a decision, and the infusion was removed. It then took another two weeks until Mrs I. died, leaving the relatives with plenty of time to come by, talk to the 
nurses, prepare for the burial, but also to be a bit puzzled about the ongoing uncertainty of their mother's status, which neither showed signs of recovery nor of suffering even after removal of the infusion.

Mrs I.'s case illustrates that if the dying individual does not or cannot express his or her wishes regarding a 'good death', it is not only challenging for the relatives, but also for the caring staff, who in such situations become more aware of their role as 'death workers'. If the loose, informal guidelines the nursing home has taken over from the palliative care model do not help to come to a more or less clear assessment of the supposed will of the dying person, and if there are no articulated alternative guidelines at hand to which one could stick (such as the relatives' guidelines in case $\mathrm{C}$ ), it seems to be very challenging to decide what to do when decisions are potentially life-threatening. Someone would have had to take over the duty of 'doing death' on behalf of Mrs I., but no one really did. Furthermore, the action upon which a decision had to be taken - the removal of an infusion - is a very invasive action, a particularly obvious form of 'doing death', which makes it even more difficult to take a decision. Pulling out the infusion is in this case comparable to the action of turning off a life-support machine, having the symbolic meaning of an agency 'deciding about life and death'. Marina struggled with this aspect of professional agency and the inherent pressure in 'death work' to take decisions having potentially severe and irreversible consequences. She questions the hesitant strategies of both doctor and relatives, trying to explicitly negotiate who is in charge of taking decisions on behalf of Mrs. I., while the evidence of what Mrs I. would have regarded as a 'good death' was completely unclear. In Mrs I.'s case, time was on Marina's side, giving her the opportunity to articulate her unease, to critically debate professional roles and powers and to insist on finding solutions mutually agreed upon, thus preventing her from feeling guilty about having taken a potentially wrong decision.

\section{The art of endurance in challenged 'death work'}

By presenting four case studies, we intended to illustrate four possible lines of collision regarding what a 'good death' is and how professional procedures of 'doing a good death' may be disturbed in contexts of societal diversities. Focusing on the "death workers" perspective, the cases point to different strategies of dealing with disturbed routines. While case $A$ is characterised by the need to be able to acquiesce and endure if a resident insists on a way of 'good death' which is incompatible with professional procedures, the following three cases are all characterised by a dying resident who lacks autonomy as a consequence of the severely constrained ability to show or articulate wishes, a situation which is rather typical in nursing homes. Issues of acting as a proxy on behalf of the 'non-self-determined' resident are at stake in all these cases, and collisions occur between 'death workers' and relatives as well as among 'death workers', as we plan to further elaborate in the future. In these cases, strategies to alleviate collisions are used to maintain or to re-establish professional agency. In case B, the 'death workers' impose their power on the relatives and stick to their routines in the process of dying, but attempt to alleviate their sense of culpability later by handing over agency to the relatives when it comes to the procedures of treating the dead body. Case $C$ is characterised by a constant but in the end unsuccessful negotiation between the 'death workers' and the relatives on what a 'good death' for the 
resident should be like. In surrendering to the relatives, the professional 'death workers' somehow also fail to protect the resident from what they regard as violating his right to have a 'good death'. Case D shows that 'death work' on behalf of 'non-self-determined' residents is constantly threatened by doing the wrong things and thereby provoking fatal consequences. Here the actors involved implicitly try to avoid making important decisions and in so doing to avoid potential guilt.

'Doing good death' is in all four cases subject to debates since the actors involved refer to 'ontological securities' which are not necessarily congruent. In other words, implicit conceptions of human agency towards issues of life and death may be diverse. Yet, condensing such diversities down to clear 'cultural' categories is not possible due to the complexity and individuality of ontological reference points. Therefore, as Gunaratnam (2008) has shown in detail, reference to 'cultural knowledge' is not in itself helpful in concrete 'death work' (see also Kai et al. 2007). The everyday interactions of professional carers', residents' and relatives' 'doing death' are always threatened by insecurities that question routinised procedures: not only with regard to professional 'death workers', as Gunaratnam (2008) has shown, but also with regard to residents and especially relatives acting as proxies. Dealing with 'ontological insecurities' in 'dying trajectories' may lead to a variegation of agency, ranging from explicit agency (as for example the relatives in case C) to incapability of agency (as in case D). The specificity of professional 'death work' in contrast to the agency of residents and relatives is, however, that agency must be maintained or regained even in circumstances of severe 'ontological insecurity', in order to fulfil the professional requirements of 'death work' and to enable the carer to move on to the next resident and their particular 'dying trajectory' (see also Kai et al. 2007). Therefore, 'deaths' constantly have to be 'done' with reference to past and future deaths, and making them 'good' is never accomplishable without some doubts potentially arising in the minds of the actors involved (see also Salis Gross 2001).

As has been shown, the dilemma described above - between the requirements of the 'total institution' asking for routinised agency and the requirements of 'good death' to provide individualised dying in dignity - is constant and cannot be resolved under the current conditions of modern societies. Furthermore, our case studies show that negotiations about 'difference' in practices of 'doing death' are not a simple matter of clearly definable cultural or migrant backgrounds, but a matter of plurality and individual autonomy in contemporary societies (see also McNamara 2004). Drawing a clear line between diversities within and beyond societies - simply put, between non-migrants and migrants - is a complex thing, and lines of collision do not stick to clear-cut non-migrant or migrant specific reference systems, but become blurred and multifaceted in everyday practice. It is, for example, the 'not so foreign' German resident in case A, belonging to a Protestant Free Church, who challenges the nursing home with rigorous religious argumentation. And while the actors in case $\mathrm{C}$ refer to stereotyping ethnic explanations for their diverging ideas on what 'good' care for a dying person is, 'ethnic sameness' on the Mediterranean ward does not facilitate decision-making in case D. While the carer in that case refers to her professionalism to justify not being able to decide, case B illustrates precisely how taking decisions at the end-of-life is associated with guilt. At the same time, case B also demonstrates that 'doing good death' is related to power and resources. 
Therefore, 'doing good deaths' in contemporary nursing home 'death work' is about being able to endure the fact that contradictions may arise at any time in 'dying trajectories'. An open awareness of this dilemma, and the provision of instruments to reconstitute agency (or to re-establish 'ontological security') for institutional 'death workers' who are always at risk of being left with feelings of unease or guilt, may be crucial to enable 'good deaths' for increasingly diversified nursing home populations.

\section{Acknowledgements}

We would like to thank our colleague Alistair Hunter and the two anonymous reviewers for their valuable comments on earlier versions of this paper.

\section{Disclosure statement}

No potential conflict of interest was reported by the authors.

\section{Notes on contributors}

Eva Soom Ammann, Dr phil., Gabriela Rauber, MA, and Corina Salis Gross, Dr phil., are social anthropologists conducting research on dying and diversity in long-term elder care. Corina Salis Gross and Eva Soom Ammann are senior researchers working in the fields of Medical Anthropology, Migration Studies, Public Health and Health Care. Their research activities include both basic and applied research regarding health care for underserved and hard-toreach groups, migrant and ageing populations, issues of diversity and inequality, dying and death. Gabriela Rauber is working on a doctoral thesis that focuses on exchange relationships in the context of institutional 'doing death'.

\section{Contact}

Eva Soom Ammann, Dr. phil., Institute of Social Anthropology, University of Bern, Lerchenweg 36, CH-3000 Bern 9, Switzerland, eva.soom@anthro.unibe.ch

\section{References}

Ariès, P., 1981. The Hour of Our Death. London: Allen Lane.

Bonss, W. and Lau, C. eds., 2011. Macht und Herrschaft in der reflexiven Moderne. Weilerswist-Metternich: Velbrück Wissenschaft.

De Graaff, F. M., Francke, A. L., van den Muijsenbergh, M.A. and van der Geest, S., 2010. 'Palliative care': a contradiction in terms? A qualitative study of cancer patients with a Turkish or Moroccan background, their relatives and care providers. BMC Palliative Care 9/19. doi:10.1186/1472-684x-9-19

Dresske, S., 2005. Sterben im Hospiz. Der Alltag in einer alternativen Pflegeeinrichtung. Frankfurt: Campus. 
FOPH Federal Office of Public Health and CMH Swiss Conference of the Cantonal Ministers of Public Health, 2012. National Guidelines for Palliative Care. Bern: FOPH.

Giddens, A., 1984. The Constitution of Society, Outline of the Theory of Structuration. Cambridge: Polity Press.

Giddens, A., 1991. Modernity and Self Identity. Cambridge: Polity Press.

Glaser, B. G. and Strauss, A. L., 1968. Time for Dying. Chicago: Aldinge.

Goffman, E., 1961. Asylums: Essays on the Social Situation of Mental Patients and Other Inmates. New York: Doubleday Anchor.

Green, J. W., 2008. Beyond the Good Death. The Anthropology of Modern Dying. Philadelphia: University of Pennsylvania Press.

Gunaratnam, Y., 2008. From competence to vulnerability: Care ethics, and elders from racialized minorities. Mortality, 13, pp. 24-41. doi:10.1080/13576270701782969

Hahn, A. and Hoffmann, M., 2009. Der Tod und das Sterben als soziales Ereignis. In: C. Klinger, ed. 2009. Perspektiven des Todes in der modernen Gesellschaft. Wien: Boehlau, pp. 121-144.

Hart, B., Sainsbury, P. and Short, S., 1998. Whose dying? A sociological critique of the 'good death'. Mortality, 3 (1), pp.65-77. doi:10.1080/713685884

Hoepflinger, F., Bayer-Oglesby, L. and Zumbrunn, A., 2011. Pflegebeduerftigkeit und Langzeitpflege im Alter. Aktualisierte Szenarien fuer die Schweiz. Bern: Huber.

Hoffmann, M., 2011. "Sterben? Am liebsten ploetzlich und unerwartet". Die Angst vor dem "sozialen Sterben". Wiesbaden: VS Verlag für Sozialwissenschaften.

Kai, J., Beavan, J., Faull, Ch., Dodson, L., Gill, P. and Beighton, A., 2007. Professional Uncertainty and Disempowerment Responding to Ethnic Diversity in Health Care: A Qualitative Study. PLOS Medicine, 4 (11), e323. doi:10.1371/journal.pmed.0040323

Kellehear, A., 2007. A Social History of Dying. Cambridge: Cambridge University Press.

Kostrzewa, S. and Gerhard, C, 2010. Hospizliche Altenpflege. Bern: Huber.

Kruse, A., 2007. Das letzte Lebensjahr. Zur koerperlichen, psychischen und sozialen Situation des alten Menschen am Ende seines Lebens. Stuttgart: Kohlhammer.

McNamara, B., 2004. Good enough death: autonomy and choice in Australian palliative care. Social Science \& Medicine 58 (2004), pp. 929-938. doi:10.1016/j.socscimed.2003.10.042

Pleschberger, S., 2007. Dignity and the challenge of dying in nursing homes: the residents' view. Age and Ageing, 36, pp. 197-202. doi:10.1093/ageing/afl152

Salis Gross, C., 2001. Der ansteckende Tod. Eine ethnologische Studie zum Sterben im Altersheim. Frankfurt: Campus.

Schneider, W. and Stadelbacher, S., 2012. Alter und Sterben anders denken - Soziologische Anmerkungen zur Zukunft des Lebensendes. Die Hospizzeitschrift, 2012 (3), pp. 6-11.

Seale, C. and van der Geest, S., 2004. Good and bad death: Introduction. Social Science \& Medicine 58 (2004), pp. 883-885. doi:10.1016/j.socscimed.2003.10.034 
Soom Ammann, E. and Salis Gross, C., 2014. Palliative Care und Migration. Literaturrecherche zum Stand der Forschung einer diversitätssensiblen Palliative Care. In: Salis Gross, C., Soom Ammann, E., Sariaslan, E. and Schneeberger Geisler, S., 2014. Chancengleiche Palliative Care. Bedarf und Bedürfnisse der Migrationsbevölkerung in der Schweiz. Muenchen: AVM, pp. 101-200.

Simpson, B., 2001. Making 'bad' deaths 'good': The kinship consequences of posthumous conception. The Journal of the Royal Anthropological Institute, Vol. 7 No. 1, pp. 1-18. doi:10.1111/1467-9655.00047

Spruyt, O., 1999. Community-based palliative care for Bangladeshi patients in east London. Accounts of bereaved carers. Palliative Medicine, 13, pp. 119-129.

Sudnow, D., 1967. Passing on: the social organization of dying. Englewood-Cliffs: PrenticeHall.

van Holten, K. and Soom Ammann, E., 2015. Negotiating the potato: the challenge of dealing with multiple diversities in elder care. In: Schweppe, C. and Horn, V. (eds.). Transnational Aging - Current Insights and Future Challenges. Routledge Series "Research in Transnationalism", pp. 200-216.

Walter, T., 2012. Why different countries manage death differently: a comparative analysis of modern urban societies. The British Journal of Sociology, 63, pp. 123-145. doi:10.1111/j.1468-4446.2011.01396.x

West, C. and Zimmerman, D.H., 1987. Doing Gender. Gender \& Society. Official publication of sociologists for women in society 1 (1987), pp. 125-151. 